\title{
MISMATCH IN EARLY LIFE TRAITS BETWEEN SETTLERS AND RECRUITS IN A MEDITERRANEAN FISH: CLUE OF THE RELEVANCE OF THE SETTLEMENT TAIL?
}

\author{
Antonio DI FRANCO ${ }^{1,2^{*}}$, Fabrizio GIANNI ${ }^{1,2}$, and Paolo GUIDETTI ${ }^{1,2}$ \\ ${ }^{1}$ University Nice-Sophia Antipolis, Faculty of Sciences, EA 4228 ECOMERS, Nice, France \\ ${ }^{2}$ CoNISMa (National Inter-University Consortium for Marine Sciences), Rome, Italy
}

\begin{abstract}
Di Franco A., Gianni F., Guidetti P. 2015. Mismatch in early life traits between settlers and recruits in a Mediterranean fish: Clue of the relevance of the settlement tail? Acta Ichthyol. Piscat. 45 (2): $153-159$.
\end{abstract}

Background. Life stage transitions (e.g., settlement and recruitment), characterized by high mortality rates, act as selective bottlenecks for fishes with a bipartite life cycle. Mortality at these stages is usually selective and potentially affected by larval history. This process is reflected in an inconsistency in larval traits' distribution between subsequent life stages (e.g., settlers and recruits) originating from the same reproductive season. Despite the importance of this issue only very scarce information is available about this aspect of Mediterranean fishes life histories.

Material and methods. Here we described settlement and investigated the match/mismatch of larval traits between settlers and recruits coming from the same reproductive season, using the white seabream, Diplodus sargus sargus (Linnaeus, 1758), as a model species along $200 \mathrm{~km}$ of the Apulian Adriatic coast (south-western Adriatic Sea, Italy). Both microstructure and chemistry analyses were carried out on otoliths of settlers $(n=140)$ and recruits $(n=113)$.

Results. We highlighted a mismatch in two life traits, i.e., PLD (pelagic larval duration) and natal origin, between settlers and recruits. Recruits showed PLD longer than the maximum recorded for settlers, and a higher number of natal sources compared to settlers. Mismatch in PLD could suggest selective juvenile mortality related to PLD, and recruits with higher PLD potentially originated from the settlement tail (i.e., settled after the settlement peak). Conclusion. Our findings can support hypotheses suggesting that 1) a fraction of juveniles are selectively eliminated; 2) settlement tail could play a relevant role in replenishing local populations of white seabream.

Keywords: coastal fish, white seabream, Diplodus sargus sargus, pelagic larval duration, natal origin, settlement, otolith

\section{INTRODUCTION}

Life stage transitions can act as major demographic and selective bottlenecks for species with complex life cycles (Samhouri et al. 2009). For coastal fishes encompassing a bipartite life cycle, with a larval planktonic stage followed by a juvenile-adult demersal stage, transition phases are represented by settlement (the shift from the planktonic to demersal habitat that usually coincides with the metamorphosis of larvae into juveniles) (Levin 1994) and the recruitment (the phase when juveniles join the adult fraction of the population) (Forrester 1990). Both settlement and recruitment may critically influence fish population size and demography (Doherty and Fowler 1994, Carr and Syms 2006, Fontes et al. 2009), and ultimately shape the structure of fish assemblages (Shima 2001, Hixon et al. 2002, Almany and Webster 2006).
Although life stage transitions only account for a small proportion of whole life span, these phases are usually characterized by high mortality rates (Doherty et al. 2004, Vigliola et al. 2007). Specifically, within the first weeks after settlement individuals massively die (up to $90 \%$ ), with some species showing about 60-percentage-point losses during the first night after settlement (Planes et al. 2009).

There is a widespread belief that overall mortality at this stage results from the combination of random mortality and selective mortality (Good et al. 2001), with the contribution of each component depending on a multitude of ecological and environmental features (Sinclair et al. 2002, Swain et al. 2007, Samhouri et al. 2009). Random mortality (the process of removal of individual fish that is not related to any life trait, with all fish displaying the same probability of dying) (Good et al. 2001) or selective 
mortality (the removal of fish related to some life traits, with some fish that are more likely to die than others) may affect the number of individuals reaching the adult phase, as well as the phenotypes of those individuals (e.g., size, Gagliano et al. 2007, McCormick 2009, Planes et al. 2009). A large suite of papers, from both tropical and temperate areas, highlighted that post-settlement mortality mainly acts through a selective process (Gagliano et al. 2007, McCormick 2009, Planes et al. 2009 and references therein). A number of larval life traits (e.g., size at hatching, larval growth rate, pelagic larval duration) has the potential to determine which individuals have more chances to survive to the next life-history stage. Therefore, the survival rate at the post-settlement stage of many fishes is not decoupled from prior life history and early life-traits from one life stage can 'carry over' to affect the fitness of subsequent developmental stages by driving a selective mortality (Smith and Shima 2011). The result of this process is an inconsistency in larval life-traits' distribution between specimens coming from the same reproductive season (i.e., the same annual cohort), but belonging to different life stages (e.g., larvae, settlers, recruits) (Smith and Shima 2011). We can distinguish three different patterns of this inconsistency, depending on the type of selection occurring (see Brodie et al. 1995 for a detailed discussion). In brief, in case of directional selection (selection for higher or lower life-trait values, also named linear selection) we can highlight an inconsistency in mean values, when stabilizing selection (selection against extreme life-traits values) occurs a decrease in variance of life traits arises and in case of disruptive selection, that acts against the intermediate life traits, an increase in the variance of life traits arises (Brodie et al. 1995). Stabilizing and disruptive selections are known as non-linear selections.

To investigate this issue, the back-calculation of larval life traits (e.g., size at hatching, larval growth rate, pelagic larval duration) from otoliths represents a powerful tool to compare life traits' distribution across life stages. This possibly enables to infer early life history traits potentially influencing juvenile survival (i.e., of those individuals that differ among life stages coming from the same annual cohort) (Searcy and Sponaugle 2001, Vigliola and Meekan 2002, Raventos and Macpherson 2005, Jenkins and King 2006).

Despite the relevance of this issue, only very few observations refer to the Mediterranean Sea and few evidences exist about differences in early life traits between specimens at different life stages, coming from the same reproductive season (see Raventos and Macpherson 2005, Planes et al. 2009).

The aim of the presently reported study was therefore to describe the settlement event (in terms of temporal window) and then investigate the match/mismatch of larval life history traits among two life stages (i.e., settlers and recruits) coming from the same reproductive season by using the white seabream, Diplodus sargus sargus (Linnaeus, 1758), as a model species. Specifically, we focus on pelagic larval duration (i.e., the duration in days of the period between hatching and settlement, hereinafter PLD) and na- tal origin (estimated through otolith chemistry) (Green et al. 2009). Here we consider PLD as a proxy describing the processes (e.g., larval growth) and phenotypes (e.g., site at settlement) related to larval history, potentially influencing individual performance and survival (Hamilton et al. 2008). Therefore, for the sake of clarity, we will refer to the selection related to PLD to picture the comprehensive effect of larval history on settlers' survival.

\section{MATERIALS AND METHODS}

Study area and species. This study was carried out along $\sim 200 \mathrm{~km}$ of the Apulian Adriatic coast (South-western Adriatic Sea, Italy), namely the stretch of coast comprised approximately between San Giorgio (Bari, $\left.41^{\circ} 8^{\prime} 20.30^{\prime \prime} \mathrm{N}, 16^{\circ} 49^{\prime} 5.08^{\prime \prime} \mathrm{E}\right)$ and Conca Specchiulla (Lecce, $40^{\circ} 14^{\prime} 39.84^{\prime \prime} \mathrm{N}, 18^{\circ} 27^{\prime} 8.15^{\prime \prime} \mathrm{E}$ ).

The white seabream, Diplodus sargus sargus, was selected as a model species because it is an ecologically (Guidetti 2006) and economically relevant coastal fish, for both professional and recreational fishing (Lloret et al. 2008), and because a number of ecological and biological information are available for this species in the investigated area.

The white seabream, that clearly responds to protection from fishing by increasing in density and size (Guidetti 2006, Guidetti and Sala 2007, Di Franco et al. 2012a, 2013), usually inhabits the littoral zone in shallow waters down to about $50 \mathrm{~m}$ (Tortonese 1965, Harmelin-Vivien et al. 1995). Adults produce eggs and larvae that develop in pelagic waters for a period ranging from 13 to 28 days (Macpherson and Raventos 2006, Di Franco and Guidetti 2011, Di Franco et al. 2011) and that are able to disperse over hundreds of kilometres (Di Franco et al. 2012a, 2012b, Pujolar et al. 2013). Then larvae metamorphose and settle at about $1 \mathrm{~cm}$ total length (TL) in shallow (about $2 \mathrm{~m}$ depth) coastal benthic habitats, mainly within small bays with mixed sand and rocky bottom (Tortonese 1965, Harmelin-Vivien et al. 1995; see Bussotti and Guidetti 2011 for specifi c evidence referred to the study area). Juveniles recruit to the adult population when they reach approximately 6-7 cm in size, $\sim 5-6$ months after settlement (Macpherson 1998), dispersing from settlement to recruitment sites over up to tens of kilometres (Di Franco et al. 2012b).

Data collection. One hundred forty settlers of Diplodus sargus sargus (i.e., $1-1.5 \mathrm{~cm}$ TL) were collected between 8 June and 15 June 2009, approximately 10-14 days after the settlement peak, occurred at the end of May-very beginning of June 2009 (Di Franco et al. 2013). Settlers were collected using a dip net at 14 sampling sites along the study area, with 10 settlers collected at each site. We did not collect settlers belonging to the 'settlement tail' (i.e., ending phase of the settlement period). Then, at beginning of November 2009, approximately 5 months after settlement peak, 113 recruits of white seabream (i.e., 6-8 $\mathrm{cm}$ TL) were caught by spearfishing at 12 of the sampling sites where settlers were collected, because of the absence of recruits in the remaining two sites. At each site between 6 and 10 recruits were collected. Each sampling site was separated by $1-8 \mathrm{~km}$ from the closest site. Sampling sites were spread along the entire study area (Fig. 1). 


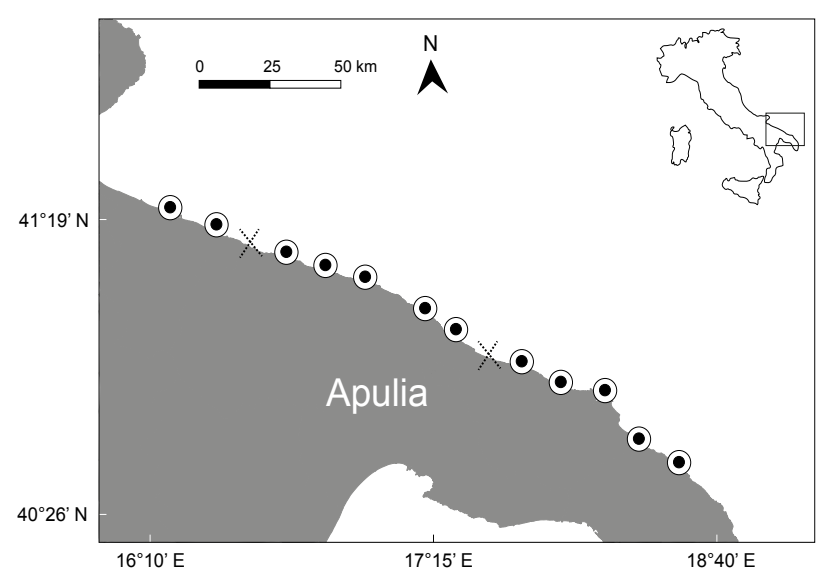

Fig. 1. Study area; Sampling sites where both settlers and recruits of white seabream, Diplodus sargus sargus, were collected are indicated with white and black circles, while sampling sites where only settlers were collected are indicated with " $\mathrm{x}$ "

One sagittal otolith was removed from each specimen (both settlers and recruits) and processed following standard procedures to assess:

- PLD and settlement date by analysing otolith microstructure (Green et al. 2009; see Di Franco and Guidetti 2011 for specific details; and

- Homogeneity/heterogeneity of natal origin analysing otolith core microchemical composition (Green et al. 2009); see Di Franco et al. (2012b) and Di Franco et al. (2014) for specific details about settings used in this analysis.

No selection was made between left and right sagittal otolith of each specimen, because a preliminary analysis (Di Franco and Guidetti, personal observation) did not highlight any variability in PLD reading between the two sagittal otoliths of the specimens of Diplodus sargus sargus.

In brief, each sagitta was mounted sulcus side up onto a glass slide and it was polished with $3 \mu \mathrm{m}$ and $1 \mu \mathrm{m}$ Imperial lapping film to expose inner growth layers for analysis.

To estimate PLD and settlement dates, after polishing, we used a standard technique of analysis of daily rings (or growth increments) on otoliths (Green et al. 2009). Otoliths develop around a primordium, which forms during the embryonic development, and grow by apposition of daily rings. PLD can therefore be accurately assessed by counting the number of daily rings between the primordium and the settlement mark (i.e., the first major transitional point). Settlement date was back calculated in settlers by subtracting the number of juvenile rings (i.e., rings located after the settlement mark) to the sampling date. The daily rings of each sagitta were read using a high-powered microscope $(\times 400)$. Each otolith was read by three independent readers, and only when the three were in agreement the otolith was used on subsequent analyses.

To assess natal origin after polishing with lapping film, sagittae were rinsed and sonicated for $10 \mathrm{~min}$ in ultra-pure water and then were analysed for the chemical composition of the core, by using ICP-MS coupled with laser ablation (LA-ICPMS) (see Green et al. 2009 for further details about the rationale behind otolith chemistry analysis). We isolated the material associated with the core using three discrete vertical pits of $30 \mu \mathrm{m}$ from the surface of the otolith through the visible core. The spike in the $\mathrm{Mn}$ : Ca ratio was used as an indicator of the core location (Ruttenberg et al. 2005) and therefore just one out of the three pits (the one showing at least 3-fold higher $\mathrm{Mn}: \mathrm{Ca}$ concentration than surrounding material) was considered in subsequent analysis. An Mn : Ca spike could not be detected in about $9 \%$ (10 samples) of the core samples of recruits; these samples were excluded from further analysis of natal origins.

Statistical analyses. We compared frequency distributions of PLD of recruits with frequency distributions of PLD of settlers to test for match/mismatch in this early life trait. PLD distributions (recruits versus settlers) were compared using the non-parametric Kolmogorov-Smirnov two-sample test owing to its sensitivity to changes in location, dispersion, and skewness of the distributions, while making no assumptions on the distribution of data (Sokal and Rohlf 2001). The significance of all comparisons was based on an alpha-level of 0.05 . We tested for potential differences in PLD of settlers and recruits by using oneway PERMANOVA.

We estimated the intensity of linear selection ( $\mathrm{Si}$, total change in the mean phenotype between the two stages investigated) and nonlinear selection ( $\mathrm{Ci}$, total change in the variance of a trait within a generation after adjusting for directional selection) related to PLD following Gagliano et al. (2007).

Linear regression analysis (DISTLM) was used to assess the relations between the settlement dates and the PLD values.

Information about potential match/mismatch of natal origins was obtained determining the number of potential natal origins in recruits (assessing micro-chemical fingerprint of otolith core) and then comparing it (in the discussion section) with the number of potential natal origins of settlers previously reported in Di Franco et al. (2012b).

To determine the number of potential natal origins of recruits, the core elemental concentrations of recruits, used as a proxy for identifying the existence of single or multiple areas of origin, were analysed by cluster analysis. The similarity profile permutation test (SIMPROF) procedure was used to determine which clusters were significantly different at the 5\% level (Clarke et al. 2008). We tested for multivariate dissimilarity in chemical fingerprint of individuals from each of the four major natal origins (see results) by using one-way PERMANOVA. Natal source was treated as a single factor with four levels corresponding to the four major natal sources identified. Elemental/Ca ratios that contribute to the significant differences among the major natal origins were identified using similarity percentage (SIMPER).

We tested for potential differences in PLD of individuals from different major natal origins by using one-way PERMANOVA.

Statistical analyses were run using Primer 6 PERMANOVA+ software package. 


\section{RESULTS}

Settlement dates, assessed from otolith samples taken from settlers, ranged from 21 May to 10 June, covering a total of 21 days. About $65 \%$ of settlement dates occurred from 28 May to 1 June, this stint corresponding to the settlement peak in 2009 (Fig. 2). No relation between settlement date and PLD of settlers was observed ( $n=140$, pseudo-f: $1.51, P=0.22$, Fig. 3 ). The individuals that settled during the settlement peak displayed the highest variability in PLD with values ranging between 13 and 19 days (Fig. 3).

On the whole settlers showed a PLD of $16.4 \pm 0.1$ days (mean $\pm \mathrm{SE}$ ), ranging from 13 to 19 days, and recruits showed a PLD of $17.8 \pm 0.4$ days, ranging from 13 to 28 days (Fig. 4). A significant difference was highlighted in PLD values between settlers and recruits (one-way PERMANOVA, pseudo-f: 14.686; $P<0.0001$ ). Recruits displayed a frequency distribution of PLD significantly different from the one of settlers (Kolmogorov-Smirnov test, $P<0.001)$. PLD of 17 days, that represented the PLD modal class for settlers (36.4\%), accounted only for $7.9 \%$ of recruits. The PLD modal class for recruits was 15 days, accounting for about $10 \%$ of recruits. About $36 \%$ of recruits showed a PLD $\geq 20$ days.

The intensities of linear and nonlinear selection related to PLD between settlers and recruits were respectively $\mathrm{Si}$ $=0.97$ and $\mathrm{Ci}=13.8$.

SIMPROF analysis detected seven statistically different groups based on the otolith core chemical composition of recruits, which possibly suggests the existence of seven different natal origins. Two groups were composed each by a single recruit (accounting on the whole for $\sim 2 \%$ of total recruits), a group was composed by three recruits $(3.22 \%)$, while the other 4 major groups accounted for the $6.4 \%, 13.9 \%, 18.2 \%$, and $55.9 \%$ of recruits.

The four major natal origins significantly differed from each other in terms of their multivariate core elemental fingerprints (PERMANOVA $P<0.01$ ). The $\mathrm{Mg}$ : $\mathrm{Ca}, \mathrm{Sr}$ : $\mathrm{Ca}$, and $\mathrm{Zn}$ : Ca ratios contributed most to the differentiation of these four major groups $(92 \%-99 \%$ of the total dissimilarity in pairwise comparisons, SIMPER analysis).

Considering PLD, no significant difference was detected among the four major natal origins, with $16.3 \pm 1.4$ (mean \pm $\mathrm{SE}), 18.1 \pm 1.1,17.8 \pm 0.4$, and $18.4 \pm 1.3$ days, respectively.

\section{DISCUSSION}

The presently reported study revealed a mismatch in two life traits (PLD and natal origin) between settlers and recruits of the white seabream Diplodus sargus sargus, in 2009 reproductive season in SW Adriatic Sea. Specifically, a fraction of recruits showed PLD values longer than the maximum PLD recorded for settlers, and originated from more natal sources compared to the ones of settlers ( 7 for recruits vs. 3 for settlers, as showed in the presently reported study and in Di Franco et al. 2012b).

Theoretically, the comparison between two subsequent life stages, indispensable to compare early life traits' distribution and infer about selective mortality, would imply to consider a representative sample of each life stage for

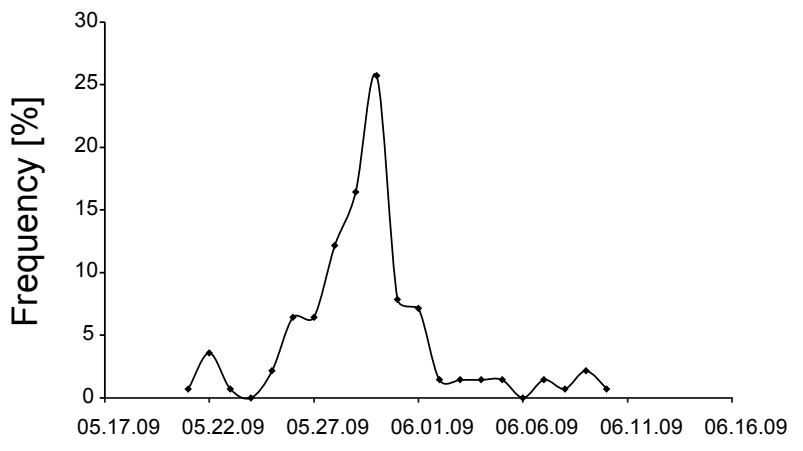

Settlement date

Fig. 2. Date frequency (mm.dd.yy) chart for settlement of white seabream, Diplodus sargus sargus, assessed from otoliths of settlers; Frequency was calculated on a daily interval

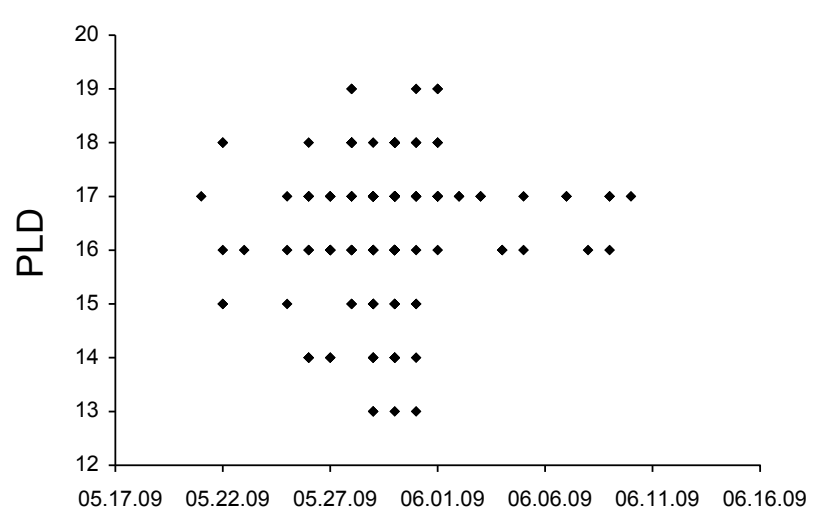

\section{Settlement date}

Fig. 3. Plot of settling dates (mm.dd.yy) versus PLD (pelagic larval duration) per each settler of white seabream, Diplodus sargus sargus, estimated from otoliths of settlers; In the figure only 53 points are visible, because of the overlapping of multiple points (total $n=140$ )

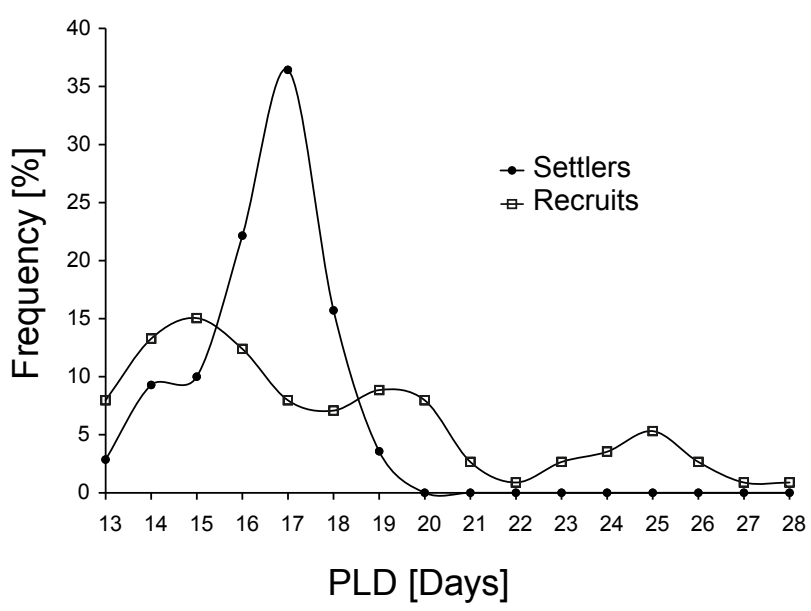

Fig. 4. Frequency chart for PLD (pelagic larval duration) assessed from settlers and from recruits of white seabream, Diplodus sargus sargus; Frequency was calculated on a daily interval 
the area investigated. In our comparison, we assumed that the settlers collected were a representative sample of the cohort that settled in the study area until the moment when collection of settlers has been done (i.e., shortly after the settlement peak). This implies that we did not sample any settler belonging to the 'settlement tail'. Individuals that settle in the tail usually account for a minimal fraction of all settlers (see Vigliola et al. 1998, Planes et al. 2009, Fernandez-Jover et al. 2009 for evidence on Diplodus sargus sargus). However, their contribution to populations' replenishment may be relevant if their mortality rate is far lower than that of other settlers. Our results suggest that individuals settled after the settlement peak could be the ones (as observed on our sampled recruits) displaying a PLD longer than the maximum PLD recorded in our samples of settlers (accounting for more than $1 / 3$ of all recruits), and originating from additional natal sources compared to the ones detected on samples of settlers and reported in Di Franco et al. (2012a). However this hypothesis should be taken cautiously and further investigated by collecting individuals along the entire settlement period, including the ones belonging to the settlement tail.

The observed mismatch in PLD could be suggestive of a selective juvenile mortality related to PLD, mainly via disruptive selection (non-linear selection, sensu Brodie et al. 1995), chiefly driving to an increase in PLD variance. This hypothesis about selective mortality related to PLD contrasts with the findings concerning non-Mediterranean species (Gagliano et al. 2007). As far as Mediterranean fishes are concerned, patterns are variable. The available results for Symphodus roissali (Risso, 1810) did not show any relation between mortality and PLD, while results for Symphodus ocellatus (Linnaeus, 1758) showed just an opposite pattern (Raventos and MacPherson 2005).

The higher survival of individuals with short and long PLD compared to those with intermediate PLD could be related to the potential correlation among PLD and sizeat-hatching, size-at-settlement, and growth rate. Some studies highlighted a negative correlation between PLD, size-at-hatching, and size-at-settlement (Raventos and Macpherson 2005). This would imply, in our case, that both smallest and largest settlers, in terms of size at settlement, have higher survival than those displaying an intermediate size. It is generally thought that larger in size and faster-growing juvenile fish are more likely to survive, with mortality being directed towards smaller and slower-growing fish. Smaller fish are more susceptible to starvation and predation: due to their lower social status and smaller size, in fact, they are often unable to successfully compete for food or shelters against predators (Good et al. 2001). Our hypothesis partially agrees with findings of Planes et al. (2009) showing a higher survival of larger individuals and an overall decrease in size variability over time at post-settlement stage for Diplodus sargus sargus.

In the presently reported study we cannot exclude that recruits showing higher PLD and a different natal origin than settlers, originated outside our sampling area and then actively dispersed within it at the post-settlement stage. Notwithstanding the fact that this bias could not be totally excluded,
Di Franco et al. (2012b) showed that only about the 7\% of recruits collected along our study area are likely to originate from settlement sites not sampled. From this perspective, this point could be considered as a minor potential bias and possibly not able to fully explain the pattern we highlighted.

The evidence of a single settlement peak for this species is in agreement with previous studies concerning the same fish (Vigliola et al. 1998, Planes et al. 2009, Fernandez-Jover et al. 2009, Bussotti and Guidetti 2011).

Based on the mismatch highlighted in this study between settlers and recruits, we can envisage that individuals settling during the settlement-tail after the peak can represent a considerable amount (almost a third) of the individuals surviving until recruitment. Both recruits with PLD longer than the maximum reported for settlers and recruits with natal origins different from the three previously highlighted for settlers in 2009 (Di Franco et al. 2012 b) are likely to come from settlers belonging to the tail. This hypothesis, if validated by further studies, would be novel and interesting to shed light on post-settlement processes possibly shaping fish population dynamics.

In conclusion, the findings of the presently reported study, showing a mismatch in early life traits among subsequent life stages of a coastal fish, may contribute: 1) to unravel the processes possibly affecting selective mortality of juvenile fish and 2) to assess the potentially relevant role of white seabream settled during the settlement-tails in replenishing local populations, possibly accounting for a considerable percentage of individuals surviving until the recruitment phase.

\section{ACKNOWLEDGEMENTS}

The authors wish to thank Cristina Melissano and Luana Dimida for the precious help during otolith preparation. Many thanks are due to Prof. Giuseppe De Benedetto and Dr. Antonio Pennetta (University of Salento, Lecce, Italy) for their invaluable help in the otolith chemistry analyses.

\section{REFERENCES}

Almany G.R., Webster M.S. 2006. The predation gauntlet: Early post-settlement mortality in reef fishes. Coral Reefs 25 (1): 19-22. DOI: $10.1007 / \mathrm{s} 00338-005-0044-y$

Brodie E.D.III, Moore A.J., Janzen F.J. 1995. Visualizing and quantifying natural selection. Trends in Ecology and Evolution 10 (8): 313-318.

DOI: $10.1016 / \mathrm{S} 0169-5347(00) 89117-\mathrm{X}$

Bussotti S., Guidetti P. 2011. Timing and habitat preferences for settlement of juvenile fishes in the Marine Protected Area of Torre Guaceto (south-eastern Italy, Adriatic Sea). Italian Journal of Zoology 78 (2): 243254.

DOI: $10.1080 / 11250001003774652$

Carr M.H., Syms C. 2006. Recruitment. Pp. 411-427. DOI: $\quad 10.1525 /$ california/9780520246539.003.0015. In: Allen L.G., Pondella D.J., Horn M. (eds.) The ecology of marine fishes: California and adjacent waters. University of California Press, Berkeley, CA, USA. DOI: $10.1525 /$ california/9780520246539.001.0001 
Clarke K.R., Somerfield P.J., Gorley R.N. 2008. Testing of null hypotheses in exploratory community analyses: Similarity profiles and biota-environment linkage. Journal of Experimental Marine Biology and Ecology 366 (1-2): 56-69.

DOI: 10.1016/j.jembe.2008.07.009

Di Franco A., Bulleri F., Pennetta A., De Benedetto G., Clarke K.R., Guidetti P. 2014. Within-otolith variability in chemical fingerprints: Implications for sampling designs and possible environmental interpretation. PLoS ONE 9 (7): e101701.

DOI: 10.1371 journal.pone.0101701

Di Franco A., Coppini G., Pujolar J.M., De Leo G.A., Gatto M., Lyubartsev V., Melià P., Zane L., Guidetti P. 2012a. Assessing dispersal patterns of fish propagules from an effective Mediterranean marine protected area. PLoS ONE 7 (12): e52108.

DOI: 10.1371 /journal.pone.0052108

Di Franco A., De Benedetto G., De Rinaldis G., Raventos N., Sahyoun R., Guidetti P. 2011. Large scale variability in otolith microstructure and microchemistry: The case study of Diplodus sargus sargus (Pisces: Sparidae) in the Mediterranean Sea. Italian Journal of Zoology 78 (2): 182-192.

DOI: 10.1080/11250003.2011.566227

Di Franco A., Di Lorenzo M., Guidetti P. 2013. Spatial patterns of density at multiple life stages in protected and fished conditions: An example from a Mediterranean coastal fish. Journal of Sea Research 76: 73-81. DOI: 10.1016/j.seares.2012.11.006

Di Franco A., Gillanders B.M., De Benedetto G., Pennetta A., De Leo G.A., Guidetti P. 2012b. Dispersal patterns of coastal fish: Implications for designing networks of marine protected areas. PLoS ONE 7 (2): e31681.

DOI: 10.1371/journal.pone.0031681

Di Franco A., Guidetti P. 2011. Patterns of variability in early-life traits of fishes depend on spatial scale of analysis. Biology Letters 7 (3): 454-456.

DOI: $10.1098 / \mathrm{rsbl} .2010 .1149$

Doherty P.J., Dufour V., Galzin R., Hixon M.A., Meekan M.G., Planes S. 2004. High mortality during settlement is a population bottleneck for a tropical surgeonfish. Ecology 85 (9): 2422-2428.

DOI: $10.1890 / 04-0366$

Doherty P., Fowler T. 1994. An empirical test of recruitment limitation in a coral-reef fish. Science $\mathbf{2 6 3}$ (5149): 935-939.

DOI: 10.1126/science.263.5149.935

Fernandez-Jover D., Sanchez-Jerez P., Bayle-Sempere J.T., Arechavala-Lopez P., Martinez-Rubio L., Lopez Jimenez J., Martinez Lopez F.J. 2009. Coastal fish farms are settlement sites for juvenile fish. Marine Environmental Research 68 (2): 89-96. DOI: $10.1016 /$ j.marenvres.2009.04.006

Fontes J., Caselle J.E., Afonso P., Santos S.R. 2009. Multi-scale recruitment patterns and effects on local population size of a temperate reef fish. Journal of Fish Biology 75 (6): 1271-1286.

DOI: $10.1111 / \mathrm{j} .1095-8649.2009 .02363 . x$

Forrester G.E. 1990. Factors influencing the juvenile demography of a coral reef fish. Ecology 71 (5): 16661681.

DOI: $10.2307 / 1937576$

Gagliano M., McCormick M.I., Meekan M.G. 2007. Survival against the odds: Ontogenetic changes in selective pressure mediate growth-mortality trade-offs in a marine fish. Proceedings of Royal Society B-Biological Sciences 274 (1618): 1575-1582.

DOI: $10.1098 / \mathrm{rspb} .2007 .0242$

Good S.P., Dodson J.J., Meekan M.G., Ryan D.A.J. 2001. Annual variation in size-selective mortality of Atlantic salmon (Salmo salar) fry. Canadian Journal of Fisheries and Aquatic Sciences 58 (6): 1187-1195. DOI: $10.1139 /$ cjfas-58-6-1187

Green B.S., Mapstone B., Carlos G., Begg G.A. (eds.) 2009. Tropical fish otoliths: Information for assessment, management and ecology. Book series: Reviews: Methods and Technologies in Fish Biology and Fisheries. Vol. 11. Springer, Dordrecht, Heidelberg, London, New York.

DOI: $10.1007 / 978-1-4020-5775-5$

Guidetti P. 2006. Marine reserves reestablish lost predatory interactions and cause community changes in rocky reefs. Ecological Applications 16 (3): 963-976.

Guidetti P., Sala E. 2007. Community-wide effects of marine reserves in the Mediterranean Sea. Marine Ecology Progress Series 335: 43-56.

DOI: $10.3354 / \operatorname{meps} 335043$

Hamilton S.L., Regetz J., Warner R.R. 2008. Postsettlement survival linked to larval life in a marine fish. Proceedings of the National Academy of Sciences of the United States of America 105 (5): 1561-1566. DOI: $10.1073 /$ pnas.0707676105

Harmelin-Vivien M.L., Harmelin J.G., Leboulleux V. 1995. Microhabitat requirements for settlement of juvenile sparid fishes on Mediterranean rocky shores. Hydrobiologia 300-301 (1): 309-320.

DOI: $10.1007 /$ BF00024471

Hixon M.A., Pacala P.W., Sandin S.A. 2002. Population regulation: Historical context and contemporary challenges of open vs. closed systems. Ecology 83 (6): 1490-1508.

DOI: 10.1890/0012-9658(2002)083[1490:PRHCAC]2.0.CO;2

Jenkins G.P., King D. 2006. Variation in larval growth can predict the recruitment of a temperate, seagrass-associated fish. Oecologia 147 (4): 641-649. DOI: $10.1007 / \mathrm{s} 00442-005-0336-5$

Levin P.S. 1994. Fine-scale temporal variation in recruitment of a temperate demersal fish: The importance of settlement versus post-settlement loss. Oecologia 97 (1): 124-133.

DOI: $10.1007 / \mathrm{BF} 00317916$ 
Lloret J., Zaragoza N., Caballero D., Riera V. 2008. Biological and socioeconomic implications of recreational boat fishing for the management of fishery resources in the marine reserve of Cap de Creus (NW Mediterranean). Fisheries Research 91 (2-3): 252-259.

DOI: $10.1016 /$ j.fishres.2007.12.002

Macpherson E. 1998. Ontogenetic shifts in habitat use and aggregation in juvenile sparid fishes. Journal of Experimental Marine Biology and Ecology 220 (1): 127-150.

DOI: 10.1016/S0022-0981(97)00086-5

Macpherson E., Raventos N. 2006. Relationship between pelagic larval duration and geographic distribution of Mediterranean littoral fishes. Marine Ecology Progress Series 327: 257-265.

DOI: $10.3354 /$ meps327257

McCormick M.I. 2009. Behaviourally mediated phenotypic selection in a disturbed coral reef environment. PLoS ONE 4 (9): e 7096.

DOI: 10.1371/journal.pone.0007096

Planes S., Lecchini D., Romans P., Mills S.C. 2009. Effects of post-settlement mortality on size and parasite load in juvenile Diplodus vulgaris and D. sargus in the Mediterranean. Aquatic Biology 6 (1-3): 153-158. DOI: $10.3354 / \mathrm{ab} 00178$

Pujolar J.M., Schiavina M., Di Franco A., Melià P., Guidetti P., Gatto M., De Leo G.A., Zane L. 2013. Understanding the effectiveness of marine protected areas using genetic connectivity patterns and Lagrangian simulations. Diversity and Distribution 19 (12): 1531-1542.

DOI: $10.1111 /$ ddi.12114

Raventos N., Macpherson E. 2005. Effect of pelagic larval growth and size-at-hatching on post-settlement survivorship in two temperate labrid fish of the genus Symphodus. Marine Ecology Progress Series 285: 205-211.

DOI: $10.3354 /$ meps 285205

Ruttenberg B.I., Hamilton S.L., Hickford M.J.H., Paradis G.L., Sheehy M.S., Standish J.D., Ben-Tzyi O., Warner R.R. 2005. Elevated levels of trace elements in cores of otoliths and their potential for use as natural tags. Marine Ecology Progress Series 297: 273-281. DOI: $10.3354 /$ meps297273

Samhouri J.F., Steele M.A., Forrester G.E. 2009. Inter-cohort competition drives density dependence and selective mortality in a marine fish. Ecology 90 (4): 1009-1020.

DOI: $10.1890 / 07-1161.1$
Searcy S.P., Sponaugle S. 2001. Selective mortality during the larval-juvenile transition in two coral reef fishes. Ecology 82 (9): 2452-2470.

DOI: $10.2307 / 2679928$

Shima J.S. 2001. Recruitment of a coral reef fish: Roles of settlement, habitat, and postsettlement losses. Ecology 82: 2190-2199.

DOI: $10.2307 / 2680225$

Sinclair A.F., Swain D.P., Hanson J.M. 2002. Measuring changes in the direction and magnitude of size-selective mortality in a commercial fish population. Canadian Journal of Fisheries and Aquatic Sciences 59 (2): 361-371.

DOI: $10.1139 / \mathrm{f} 02-015$

Smith A., Shima J.S. 2011. Variation in the effects of larval history on juvenile performance of a temperate reef fish. Austral Ecology 36 (7): 830-838. DOI: $10.1111 /$ j.1442-9993.2010.02223.x

Sokal R.R., Rohlf F.J. 2001. Biometry: The principles and practice of statistics in biological research. 3rd edn. Freeman, New York, NY, USA.

Swain D.P., Sinclair A.F., Hanson J.M. 2007. Evolutionary response to size-selective mortality in an exploited fish population. Proceedings of Royal Society B: Biological Sciences 274 (1613): 1015-1022.

DOI: $10.1098 / \mathrm{rspb} .2006 .0275$

Tortonese E. 1965. Biologie comparée de trois espèces méditerranéennes de Diplodus (Pisces, Sparidae). Rapports Commission Internationale pour l'Exploration Scientifique de la Mer méditerranée 18 (2): 189-192.

Vigliola L., Doherty P.J., Meekan M.G., Drown D.M., Jones M.E., Barber P.H. 2007. Genetic identity determines risk of post-settlement mortality of a marine fish. Ecology 88 (5): 1263-1277.

DOI: $10.1890 / 06-0066$

Vigliola L., Harmelin-Vivien M.L., Biagi E., Galzin R., Garcia-Rubies A., Harmelin J.-G., Jouvenel J.-Y., Le Direach-Boursier L., Macpherson E., Tunesi L. 1998. Spatial and temporal patterns of settlement among sparid fishes of the genus Diplodus in the northwestern Mediterranean. Marine Ecology Progress Series 168: 45-56. DOI: $10.3354 / \operatorname{meps} 168045$

Vigliola L., Meekan M.G. 2002. Size at hatching and planktonic growth determine post-settlement survivorship of a coral reef fish. Oecologia 131 (1): 89-93. DOI: $10.1007 / \mathrm{s} 00442-001-0866-4$

Received: 3 October 2014 Accepted: 17 February 2015 Published electronically: 30 June 2015 